\title{
Sustainable Development Goals, Sports and Physical Activity: The Localization of Health-Related Sustainable Development Goals Through Sports in China: A Narrative Review
}

This article was published in the following Dove Press journal:

Risk Management and Healthcare Policy

Jianhui Dai'

Rashid Menhas ${ }^{2}$

'School of Physical Education and Sports, Soochow University, Suzhou, Jiangsu Province, People's Republic of China;

${ }^{2}$ Research Center of Sport Social Sciences, School of Physical Education and Sports, Soochow University, Suzhou, jiangsu Province, People's Republic of China
Correspondence: Rashid Menhas Research Center of Sport Social Sciences, School of Physical Education and Sports, Soochow University, Suzhou, Jiangsu Province, People's Republic of China Email menhas.r@yahoo.com

\begin{abstract}
Sport has been recognized as an essential tool for the implementation of the SDGs by The Agenda 2030 for sustainable development. The Chinese government has launched a Healthy China 2030 plan in response to the health-related SDGs. The Chinese government has introduced different kinds of measures under Healthy China 2030 plan to achieve health-related SDGs through sport and physical activity. The Healthy China program is compatible with SDGs regarding health, sport, and physical activity. After introducing the program with sustainable built environment intervention for sport and physical activity, the elderly population of China is participating in sport and physical activity to improve the national fitness level and prevent NCDs. Sport is playing a vital role in preventing NCDs in the shape of increasing physical activity among the Chinese people. Sports and physical activity play a crucial role in the implementation of health-related SDGs and further help in the achievement of "Healthy China” 2030 goal. China's localization policies for the realization of SDGs have a global impact through glocalization in the BRI participant's countries and supporting them to make their public health system secure and promoting global health governance.
\end{abstract}

Keywords: Healthy China, built environment, NCDs, elderly population, glocalization

\section{Introduction}

In this paper, we analyze how physical activity and sports are helpful in achieving a healthy society under the sustainable development goals (SDGs). The SDGs introduced by the UN in 2015 and replaced the Millennium Development Goals (MDGs). The SDGs are a multidimensional strategy that focuses on socioeconomic and environmental development in a coordinated way. The goals of the SDGs are universally applicable and further provide the basis for global health development. ${ }^{1}$ The UN introduced a new set of goals in September 2015 for the guidance of global health development. ${ }^{2}$ Health promotion is the component of all the SDGs in contrast to the MDGs. The UN acknowledged Sport as a vital promoter and facilitator of SDGs. The agenda 2030 for sustainable development and SDGs summit of the UN was indicated sport as an essential contributor in every SDG. ${ }^{3}$ Physical activity and sport are significantly crucial for the improvement of health and wellbeing to achieve the MDGs. Physical activity and sports can help prevent and treat any world's leading non-communicable diseases (NCDs). Regular 
physical activity outcome shows that people who participate in the sport and physical activity have social, physical, and mental wellbeing benefits. ${ }^{4}$

The Sustainable Development Plan 2030 is acknowledged sport as "an important and cost-effective enabler" for the achievement of SDGs globally. Sport provides a "peaceful and soft way" for vital developmental actions such as sustainable environment development, education, and health promotions as mentioned in the Figure 1.

The post-2015 development agenda on sport for development shows that SDGs provide several opportunities to sport for development such as;

- The sport could establish skills and toolkits that play a substantial role in independent and healthy living and contribute to earnings-generating practices and economic participation (SDG1).

- Sport may encourage poverty eradication and raise funds and foster alliances for that aim (SDG 1). ${ }^{5}$

- Sport may stimulate global food production, food protection, a balanced diet, and organic farming. Sporting enterprises should set a precedent by purchasing food from liable suppliers and mitigating the effects of food waste (SDG 2).

- Curriculum programs focused on sports will seek to transform behavior for a sustainable society (SDG 2). ${ }^{6}$

Sustainable Development Goals (SDGs) for 2030 would obviously assist with investment in policies to promote walking, biking, sports, outdoor recreation, and play. The physical activities policy interventions have multiplicative healthcare and socioeconomic benefits. They would lead directly to SDG3 (wellness and good health), and also other goals,

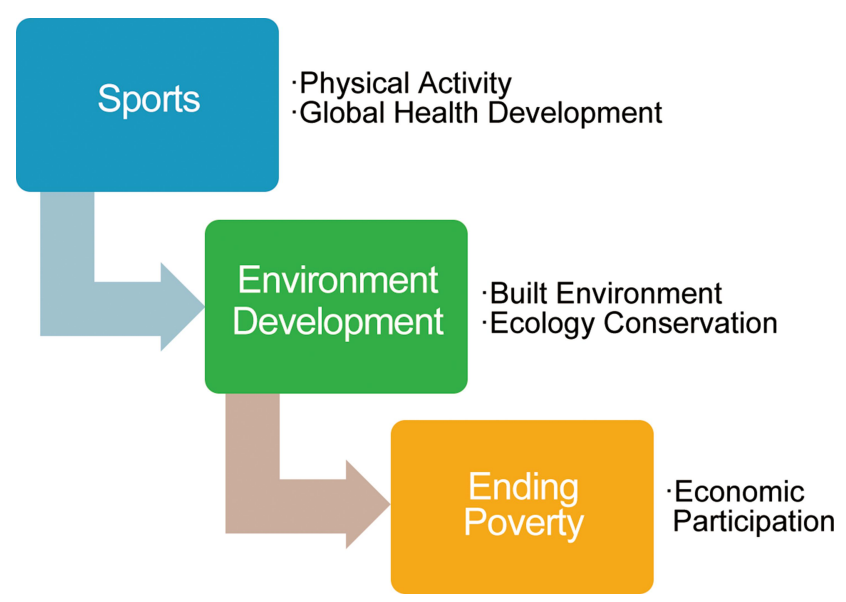

Figure I Sports contribution in vital development actions. including SDG2, for example (ending malnutrition in all aspects of health); SDG4 (education for quality); SDG5 (equality between men and women); SDG8 (decent job and economic development); SDG9 (industry, innovation, and infrastructure); SDG10 (reduced inequality).

\section{Sports and Physical Activity for Global Health and Sustainable Development}

Multidimensional new approaches for health promotion have been developed and ended the past few spans. These novel methods must base upon multilevel integrated interventions. Through enabling healthy environments through community involvement, reorientation of health services and public policies are the main emphasis to promote health and well-being., ${ }^{3,7}$ Figure 2 shows the SDGs which are linked with health promotion, sports, and physical activity;

At present, a comprehensive strategy to promote health is the establishment of healthy settings with various social and health interventions. ${ }^{8}$ The initiative of healthy cities has attracted much attention to health promotion through built environment intervention. The Shanghai Consensus on safe communities was embraced by the 9th Global Health Promotion Conference of 2016, demonstrating the close connection between smart urban growth and wellbeing. ${ }^{9}$ The observations made under the healthy cities intervention in Colombia and Chile reported that healthy cities are significantly contributing to health promotion under the SDGs. ${ }^{10}$ Health infrastructure, which includes built environment interventions for physical activity and sports, are also playing an essential role in the reduction of physical inactivity and the global burden of disease. Sedentary death syndrome is a significant cause of worldwide premature millions of death every year, which is the result of physical inactivity. ${ }^{11}$ The major actual of death is poor nutrition and physical inactivity. ${ }^{12}$

Most of the incurable diseases are regulated by evidence-based medicine and converted into disorders throughout the lifespan, as in typical cases of diabetes and renal terminal insufficiency. Acute bacterial infections, which dominate morbidity in the old days, were usually treated successfully within a few weeks. In comparison to these, chronic diseases brought long-term strain to both the patients and the community. Malignant diseases present especially daunting medical conditions with their diverse treatment approaches. Cancer leaves a patient's lasting 


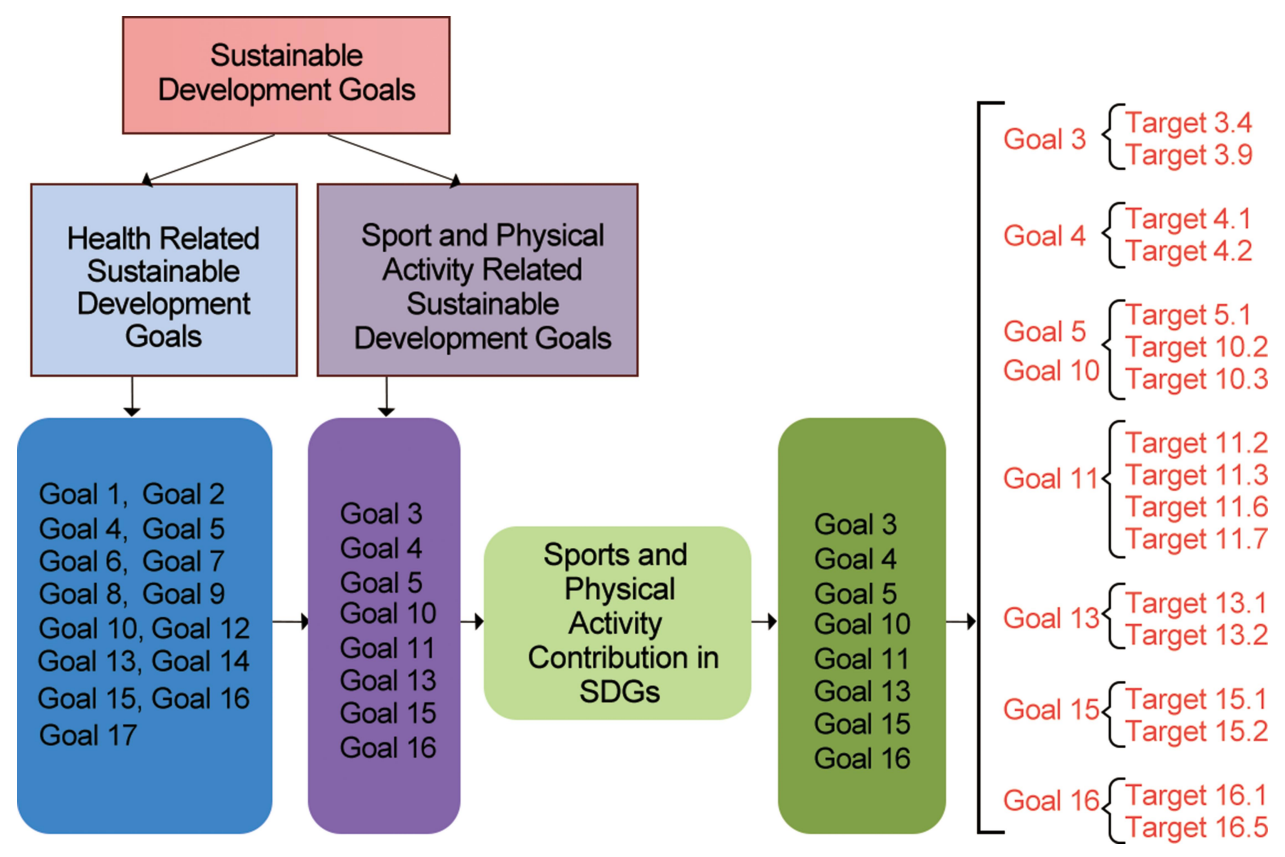

Figure 2 Health, sport, and physical activity-related SDGs.

footprint in terms of low survival rates, reduced quality of life, and ability to function. ${ }^{13}$ According to the SDGs, there are three pillars to promote good health; good governance, health literacy, and healthy cities. Knowledge, attitude, and beliefs play a vital role in the management of NCDs under health literacy. According to SDG 4, education and an effective education system that includes health literacy critical for a healthy society. In the context of health literacy, a study on dementia literacy reported that community health education programs play a significant role in enhancing people's awareness of different diseases. ${ }^{14}$

\section{The Relevance of SDGs with Sport, Physical Activity and Universal Health}

The Inter-Agency and SDG Indicators Group announced a total of 232 monitoring indicators to monitor and evaluate progress by the Member States, and 50 indicators related to health. Several initiatives to track global progress in healthrelated SDGs have been initiated, including the SDGs' monitoring of health. ${ }^{15,16}$ Global urbanization and advanced technology trends, as well as related social, lifestyle and cultural change, have led to significant declines in physical activity, contributing mainly to a health system crisis and increasing the role of sports and sporting activities in delivering critical health benefits of physical activity. ${ }^{17,18}$ The Global Action Plan on Physical Activity 2018-30 of WHO and the Kazan Action Plan 2017 of UNESCO is introduced as a global framework for sport, physical activity, and physical education under the umbrella of SDGs. A defined, interdependent, multidisciplinary approach is needed to achieve the set of objectives and targets. ${ }^{19}$ NCDs are the result of physical inactivity, which is associated with further disabilities and contributes to disease burden. The aim of SDG 3 (target 4) is specifically designed for the prevention and treatment of NCDs, which further significantly promote mental health and wellbeing. Physical activity is a universally accepted, scientifically-perceived, and economical intervention that has been demonstrated to reverse and prevent many NCDs and encourage the full range of people's health and wellbeing.

\section{Goal 3: Ensure a Healthy Life and Foster Equality for All Ages}

Sports are playing an essential rule in numerous aspects of sustainable development like sustainable tourism development through sports, promoting peace, sustainable health development through the sustainable built environment. Sport played an essential role in enhancing eight MDGs recognized in the various UN General Assembly resolutions. The resolution with the title "Transforming our world: Transforming our world: the 2030 Agenda for 
Sustainable Development", implemented in 2015. Sports promote health and wellbeing without any gender, age, or ethnic differences. ${ }^{20}$ Policymakers should introduce such actions to the population for physical activity, which will help reduce non-communicable diseases (Target 3.4) through built infrastructure that improves physical fitness level. Built infrastructure should have unbiased access to cycling and walking to reduce road accidents, particularly for those involved in cycling and pedestrians (Target 3.6). Furthermore, promote active travel mood and discourage automobile travel to improve air quality (Target 3.9). ${ }^{20,21}$ Sporting activities can help to convey health information, and sporting ventures can attract individuals who have not received traditional health education. In the treatment and rehabilitation of communicable and non-communicable diseases, exercise, physical activity, and sport have long been utilized. Individual physical activity is a healthy means of disease prevention and a cost-effective method for nations to promote health along through communities.

\section{Goal 4: Ensure Equal and Affordable Schooling for All and Promote Lifelong Learning}

According to the WHO, the ratio of inactive people is rising in high-income countries (32\% in 2001 to $37 \%$ in 2016) while it is stable in low-income countries at $16 \%$. It is found that men are more active than women in the East and SouthEast Asia. ${ }^{22}$ Young people and children get health benefits through physical activity. A comprehensive education system combined sport and physical activities with the school curriculum for healthy learning. Participation of students in athletics and physical events to practice socio-professional ideals like function as a squad, teamwork, fair play, empathy, conformity with laws, and discipline (Target 4.1, Target 4.2). For children who are unable to attend school sport offers lifelong learning and alternative training. Students are exposed to the core values of sports such as cooperation, and tolerance when participating in the sportive and physical activities alongside the school. These prerequisites are essential to future participation in group and professional activities and foster social cohesion in communities and societies.

\section{Goal 5: Gender Equality and Empower All Women and Girl}

Women and girls can be empowered through sport and physical activity, which further improves their psycho- social and health conditions. Policy decisions would be consistent with gender equality, enabling physical exercise for women and girls at reasonable costs across life. In this context, a particular focus should be on disadvantaged and marginalized communities to end the discrimination in physical activity and sports (Target 5.1). ${ }^{21}$ Stereotype and social expectations generally associated with women are often at stake in female participation in sport. By emphasizing their strengths and abilities, the sport will help women and girls show their talents and accomplishments for society. In turn, improves women's self-confidence and self-esteem. Sport also offers social experiences and bonding opportunities, which can raise knowledge of gender roles among male colleagues and provide both individuals and groups with social and psychological benefits. Furthermore, the involvement of women and girls in sports initiatives would tackle sexual and reproductive health, sexual harassment, and women's leadership.

\section{Goal I0: Reduce Inequality}

Acts for legislation maximize the physical activity and sports potential through various programs which include mega sports events to empower irrespective of individual traits and to promote inclusion which further helps in the promotion of socioeconomic and political integration (Target 10.2) and equal access (Target 10.3). ${ }^{21}$ International law is based on the right to equality and no racial discrimination. Sport can be used as a platform for promoting equality to reduce inequality. The creation of sport-related policies and programs that aim to reduce existing disparities can lead to equal opportunities within and through sport. The prevalence and optimistic attitudes towards sport make it a useful tool for resolving inequities in hard-to-reach areas and communities. It can also counter racism and bigotry by also supporting empathy and pro-social behavior.

\section{Goal I I: Making Communities Inclusive, Healthy, Productive, and Resilient}

There are several ways in which sports and physical activity contribute to a healthier community. Physical activity and sports, combined with other factors such as the built environment for sports and physical activity, promote a healthy lifestyle. A healthy urban system and ecosystem have a significant effect on fitness and physical activity participation. City projects will have equal exposure to robust and accessible walking leisure facilities and contribute to active 
travel, bicycling, and green spaces, making it possible for everybody in a particular environment (Target 11.2) and resilient urbanization (Target 11.3). Sustainable transport systems and urbanization reduce the eco-friendly influence of municipalities (Target 11.6) and further lead to universal access to public and green places (Target 11.7). ${ }^{21}$ The SDG is also referred to as "urban SDG" because it covers different aspects of urban infrastructure. The built environment includes a green setting for sports and physical activity, playing a dynamic role in active, healthier, wealthier, and safer cities. Sports programs would contribute to 'sustainable and resilient planning of and management of human settlements and the capacity to engage, integrate, and sustain. Sporting activities can also function as a tool for sustainable city growth, including enhanced road networks and public transport, thus contributing to road safety.

\section{Goal I3: Climatic Change}

To promote good health through sport and physical activity, which further reduces the burden of NCDs are linked with climatic factors such as temperature. Sport and physical activity behavior strongly influenced by climatic factors. Climate change mitigation (Target 13.1) combined educational and environmental interventions to support physical activity in the form of land, public transport, walking, and cycling. Policy actions improve awareness through education, institutional and human capacity regarding mitigation and adaptation to climate change (Target 13.2). ${ }^{21}$ The UN strongly supports the role of sport in sustainable development, and this context UN Climate Change (UNFCCC) has been developed a plan "Climate Action Sports" to empower and encourage all sports organizations to have a decisive part to play in meeting global climate change goals. Sports organizations play a vital role in the climatic change by building green infrastructure, promoting physical activity and a healthy lifestyle. In terms of energy conservation as well as water resource management, mobility, food production, carbon impact reduction, and sporting activities, the Sports world will contribute to a worldwide consensus about climate change and provide a forum for proposing sustainable solutions to climate change.

\section{Goal I 5: Land for Life}

Policies regarding natural environment ensure adequate access to, and utilization for sport, physical activity, and recreation. Sufficient access and use of natural resources can be contributed to environmental sustainability, conservation, land restoration, and biodiversity (Target 15.1).
Environmental sustainability further will assist to the inland freshwater ecosystem (Target 15.5). ${ }^{21}$ Sporting is highly dependent on the accessibility of natural resources and healthy ecosystems in daily life. The sporting world would help raise an understanding of the need to protect life on land and underwater. The natural climate is constantly improving through introducing green road interventions for physical activity to improve people's health. Energy use and carbon dioxide emissions declined from the previous year, respectively, by $3.1 \%$ and $4 \%$ in 2018 . The Chinese government has also progressed comprehensively in regulating environmental pollution and introduced the most strict water resources management program.

\section{Goal 16: Fair and Sustainable, Healthy Communities}

The 2030 Agenda for Sustainable Development recognized the contribution of sport to the realization of development and peace in its promotion of tolerance and respect and the contributions it makes to the empowerment of women and young people, individuals and communities as well as to health, education and social inclusion objective.

Policy actions ensure that sports nurture positive social values among different age group people, nationality, and political beliefs, which further contribute to the reduction of conflicts (Target 16.1), bribery, and corruption (Target 16.5) through promoting non-discriminatory social values and laws. All the above discussed SDGs in relevance to sport, physical activity, and global health are also declared in the Bangkok Declaration. These are the sustained and cost-efficient ways to promote good health through sports and physical activity interventions.

The integration of SDG and interdependence are crucial for the successful implementation and advancement of collective and individual SDG. SDG integration means to view every SDG within the linkage of other SDGs, not in isolation. Interdependence refers to an individual SDG's reliance on directly and indirectly related SDGs to meet targets. Progress in one SDG ripples to progress in related SDGs that can be leveraged throughout the SDG ecosystem for all-encompassing advancement across all SDGs. For advancing health (SDG 3), the supporting infrastructure (environment) and adequate economic growth are necessary. A brief overview of specific environmental, economic, and health factors illustrates SDGs' integration and interdependence. Health and economic environments are impacted by ecological disasters and events. Extreme 
droughts (environment), which are causing (economically) rising (economic) inflation of food and also increasing the incidence of infections (health) water shortages and impurity, can lead the latter to rapid famine and worsen poverty.

Moreover, the priority set-up and relocation (economic) of the public funds for helping displaced persons and for restore of resources at the cost of health (health) and welfare is driven by cyclones (environment) and flash floods (environment). All the above-described SDGs are integrated and interdependent to achieve the desired targets of health through sports and physical activity. Sports are playing a vital role in achieving a healthier and economically stable society by providing opportunities for income-generating, building infrastructure (environment) for promoting a healthy lifestyle, and eradicating poverty through fundraising for the deprived communities of the world.

\section{Chinese Scenario}

Nearly all the Millennium Development Goals (MDGs) have been met by China, including significant poverty reduction, increased access to elementary and secondary education, and improved environmental sustainability and equality between the sexes. Economic growth, higher public health investment, the creation of health legislation and regulations, the implementation of state-supported health insurance systems for enhancing population coverage, and multi-sector coordination and collaboration at both national and international levels are essential motivators in achieving MDGs within China. ${ }^{23}$ According to the reports of the Foreign Ministry of China, several SDGs have been achieved as "early harvest" over the past four years. Further, the Chinese government is focusing more on the promotion of physical activity through sports to achieve the SDGs. WHO Global NCD Action Plan (2013-2020) seeks to raise the amount of physical activity and physical inactivity by around $10 \%$. Increasing sedentary behavior and lifestyles are associated with rapid urbanization and modernization in China. The level of physical activity has been dropped at an alarming rate between 1991 and $2006 .{ }^{24}$ The aging population is a global phenomenon that has socioeconomic consequences related to health. China is also facing the problem of the aging population with NCDs. The Chinese government has implemented several plans to make Chinese society healthier in the context of the environment and public health. The Built Environment is promoting physical activity among the aging population of China and sports among the young generation. The trend of using parks among rapidly growing the aging Chinese people has been increased due to building Environment initiatives of the Chinese government, which is a positive indicator of the achievement of Sustainable Development Goals (SDGs). The Chinese government policies are shown in Figure 3 related to health and SDGs.

A system-based approach, combining strategic "upstream" policy action to improve socio-cultural, costeffective, and environmental aspects that support physical activity with "downstream" strategies, requires active effort at a national level to overcome current trends and to reduce disparities in physical activities. The absence of effective policy intervention is the main impediment achieving the SDGs health-related targets. The success of China in achieving the MDGs, respectively 2000 and 2015, made the world optimistic that between 2016 and 2030, it would be incredibly successful and reach the SDG objectives. China uses "health in all policies" as a priority action plan to under the SDGs to improve the public health facilities.

\section{Chinese Government Initiative for Localization of Health-Related SDGs Through Sports}

After the victory of Communist in 1949, the transformation of the Chinese culture and sports happened. Chairman Mao Zedong wrote in 1917 that the most important is physical education than moral and intellectual education. In 1951 "Radio gymnastic" was introduced to enhance the physical fitness of the Chinese nation. ${ }^{25}$ In different era's Chinese government introduced various programs for the national fitness of Chinese society through promoting sports culture

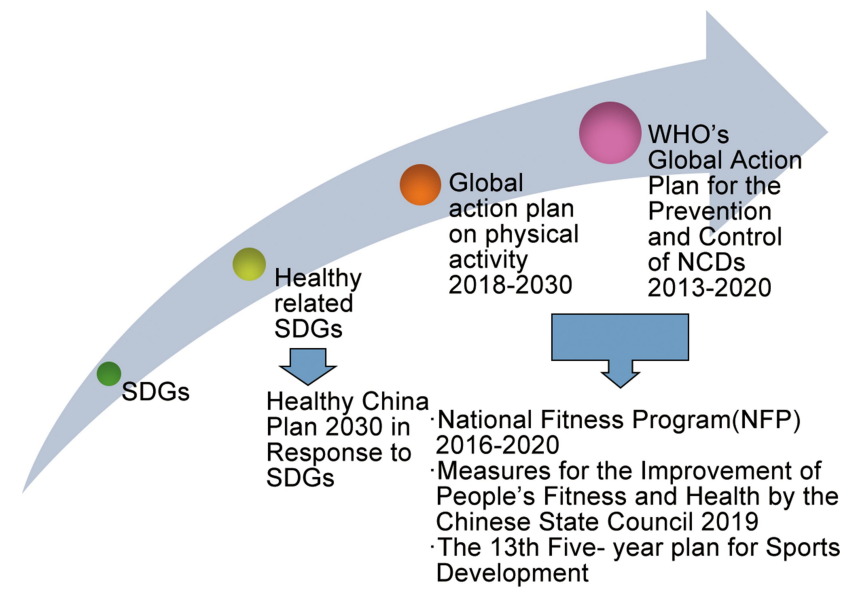

Figure 3 Chinese government initiatives in response to SDGs and WHO global action plan on physical activity. 
and physical activity. The Chinese government introduced multiple measures to increase the physical activity level for the promotion of good health under SDGs, based on the four strategic objectives (create active societies, active environments, create active people, create dynamic systems) of WHO Global Action Plan of Physical Activity 2018-30. The central facilitator or "building block" is necessary to establish the conditions needed for SDGs to be localization. These include developing, implement, and monitoring integrated approaches to SDGs. China is doing well in the localization of health-related SDGs through sports and physical activity. The names of the measures are given below;

1. The 13th Five-year plan for Sports Development

2. Healthy China 2030 (Health Infrastructure and Built Environment for Physical Activity Promotion)

3. National Fitness Program (NFP) 2016-2020

4. Measures for the Improvement of People's Fitness and Health by the Chinese State Council 2019

\section{The I3th Sports Development Five-Year Plan}

According to this plan, the sustainable development of sports in China for the achievement of national rejuvenation is the key strategy. The Beijing Winter Olympics 2022 and the Beijing Winter Paralympics are also going held during this period. The ruling Party of China and the Chinese State Council are preparing for this mega event in mainland China. ${ }^{26}$ The development of the domestic sports industry, about 5 trillion Yuan by 2025, is the critical strategy. The plan not only focused on the development of the sports industry, sports training, fitness exercise, intermediary services of sports and sports products manufacturing, but also the unified development between sports and related industries. There should also be taken measures to encourage the incorporation among sports, sports culture, creative industry, and healthcare industry. Furthermore, the development of media for sports, sports exhibitions, and sports advertising is also included in the five-year development of the 13th sport. The $13^{\text {th }}$ sports development five-year plan is contributing in the achievement of several SDGs such as SDG3 (healthy lifestyle through developing sports training and fitness exercise), SDG8 (economic development through investment in the sports industry and providing job opportunities to the public), SDG9 (industry, innovation, and infrastructure through introducing new talents) and SDG11 (healthy built environment).

\section{Healthy China 2030_A Response to Health-Related SDGs}

The SDGs are aimed at affecting all levels of society, reaching all sectors, embracing equity, inclusion, and universality. SDG 3 aims to achieve better health outcomes by reducing mortality, epidemic ending, and universal health coverage for accessible, affordable, reliable, and fair health care. SDG 3 seeks to improve health outcomes. ${ }^{27}$ The Chinese government's central plan is the development of "Healthy China" by improving the health of the Chinese people. The Chinese government approved the 'Healthy China 2030' plan to achieve UN sustainable development goals (SGDs) and to participate in Global Health Governance, as mention in Figure 4.

Universal health coverage (UHC) is one of the targets of SDG3, which is linked with economic, environmental, and health nexus. According to Figure 3, China is sharing his experience and policies at the global level in sports, physical activity, and SDGs implementation frameworks to promote global health governance. China introduced the most significant reforms in the health system to extend health facilities beyond the urban cities to improve people's lives in health paradigms. The health reforms under the Healthy China 2030 plan are according to the SDGs, which is helping to achieve the targets of Healthy China and SDGs. After introducing the reforms, now nearly $100 \%$ of the Chinese population has health insurance. China is facing the NCDs

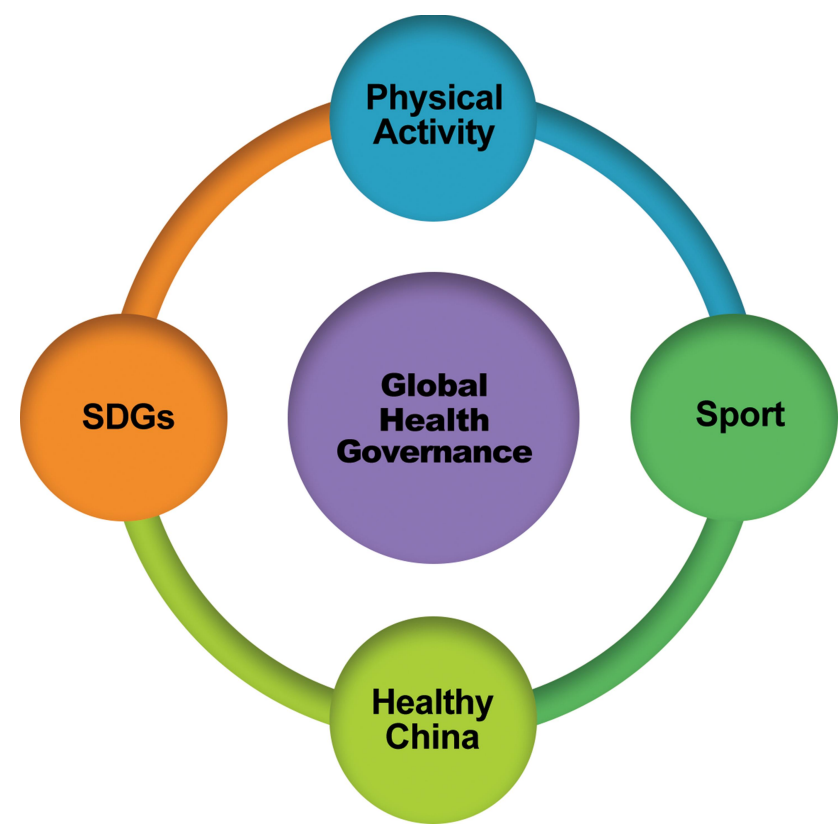

Figure 4 Global health governance. 
problem, which is linked with the aging population. The most important aspect of 'Healthy China 2030' is to promote a healthy lifestyle and physical fitness with the focus on prevention from NCDs rather than treatment. A national smoke-free law is also another significant step towards "Healthy China," which is proving helpful in the prevention of NCDs. ${ }^{27}$ China has made tremendous progress in reducing maternal mortality at a national level and has achieved MDG 5 by rising by $75 \%$ from 1990 to 2015 , the maternal mortality ratio.

\section{Glocalization of Healthy China Policies and China's Contribution to Global Health}

- Within the context of the Belt and Road Initiative, Chinese efforts are growing to improve public health in its partner countries. ${ }^{28}$ China is helping other developing countries in public health affairs. Under the Belt and Road Initiative (BRI), in multiple sectors of health, China is encouraging collaboration with other countries (SDG 17), including health crises, prevention, and control of infectious diseases, women's, and children's safety, welfare programs and policies growth and capacity-building. ChinaAustralia-Papua New Guinea triangular malaria prevention and control partnership initiative initiated in 2016. Belt and Road Initiative is highly compatible with the Agenda of 2030 SDGs, and China is promoting multidimensional sustainable development in least developed countries with the collaboration of different international health related agencies as mentioned in the Figure 5.

Chinese government signed an MOU with WHO in 2017 to construct a "Health Silk Road" for improving the public health sectors in BRI participants countries under the SDG 17. A result-oriented series of measures unveiled in May 2017 on Belt and Road Forum for International Cooperation to support the global implementation of the SGDs 2030 Agenda to promote the sustainable development in countries along the BRI route. The BRI project also offers a shared forum to enhance the capacity to manage regional crises in public health by sharing outbreak knowledge, exchanging protective and integrative approaches, and educating healthcare professionals. "Health Silk Road" along the "Digital Silk Road" is a new emerging concept, and it can play a vital role in

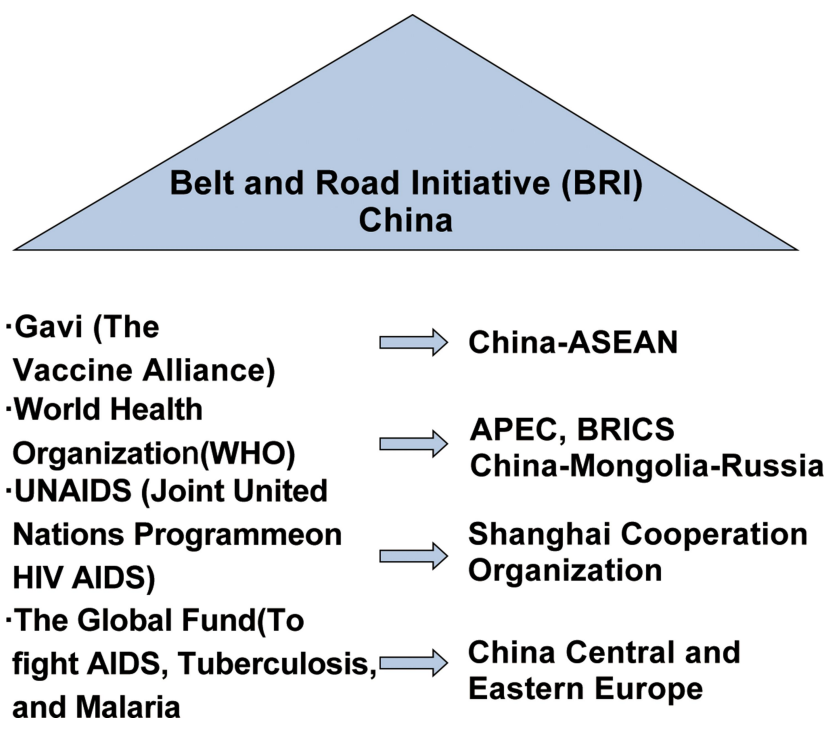

Figure 5 Glocalization of Chinese Health Policies through BRI.

sharing healthcare knowledge globally, which further promotes global health governance.

\section{National Fitness Program (NFP) 2016-2020}

Another important risk factor for poor health and chronic disease prevention and management is addressing physical inactivity, which requires primary and public health care and legislation. ${ }^{29}$ The 2016 Lancets Physical Activity Series argued that physical activity objectives must reflect and be in line with social, environmental, and sustainable development goals. ${ }^{30}$ In this paradigm, the Chinese state council introduced a national fitness strategy in June 2016 to improve the physical fitness of the whole nation and then further also improve the health level by 2020. According to this plan, it is expected that a significant increase will be held in the number of people participating in the physical exercise by 2020. The program also supports to promote and utilize the Winter sports to prepare for the Beijing 2022 Winter Olympics. The reasons for China's new fitness plan at a glance are given below in figures why the Chines government introduced this program. In China, childhood obesity is increasing due to physical inactivity. A study reveals that obesity among the Chinese children (age 7 to 18 years) from 1985 to 2014 has been increased from $0.03 \%$ to $17.2 \%$ among boys and $0.12 \%$ to $9.11 \%$ in girls. About $28.3 \%$ of China's population has an obesity problem. ${ }^{31}$ It is the first reason to implement the NFP to curb the obesity prevalence in Chinese society. The policy focuses on adolescents to promote engagement in school physical education and athletics. The 2 nd objective of 
the NFP was to increase the sports industry and fitness industry revenue. After the implementation of the program, indoor fitness apparel sales and fitness center revenue have been raised. After the execution of NFP, it is expected that sports consumption will reach about 1.5 trillion Yuan. According to the general administration of sport (GAS), national fitness plans also focus on China's rural areas. It aims to equip the villages with sports facilities, including two table tennis tables and standard size basketball ground to promote fitness nationwide. Approximately 570,000 villages throughout the country have connections to the services as mentioned earlier, and only 50,000 remain, which is not yet covered under the NFP. ${ }^{32}$

\section{Key Goals of the Plan}

1. By 2020, 700 million people will exercise at least once a week, and the number of people who regularly participate in physical exercise will reach 435 million

2. Spread health knowledge, advocate fitness, promote the new concept of physical and mental health

3. Encourage fitness nationwide by providing a variety of sports and workout activities

4. Build local fitness facilities and small to medium size stadiums

5. Expand international sports participation with programs, personnel, and equipment

6. Focus on teenagers and promote youth sports activities through strengthening physical education, sports programs and administrative accountability at school

7. Increase engagement in football (Soccer) in Winter sports

\section{Measures for the Improvement of People's Fitness and Health by the Chinese State Council 2019}

A subsequent action plan was released by the Chinese State Council after three years of the announcement of Healthy China 2030 under the title of 'improvement of people's fitness and health by the Chinese State Council 2019'. The target of the policy is to meet 15 goals between 2020 and $2030 .{ }^{28}$ Some of the main priorities are listed below;

1. To decrease the effects of second-hand smoking on health

2. To reduce obesity
3. To increase physical activity level across the country

4. To prevent non-communicable and chronic diseases

5. To prohibit unhealthy dietary behavior

The Chines government has introduced the measures mentioned above to achieve the goal of Healthy China 2030. The main agenda of all these measures is to increase the physical activity level and sports participation of the Chinese nation to fight against NCDs and achieve healthrelated SDGs targets.

\section{Sports-Environment, Health, and SDGs}

In developed countries, increasing sedentary lifestyle prevalence are a significant challenge. The sedentary lifestyle is the leading factor in the incidence of NCDs. The one recommended solution from avoiding the NCDs is to participate in sports and physical activity. ${ }^{33}$ The problem of physical inactivity is experiencing from the last 15 years. The Chinese government introduced a national fitness plan (NFP) to improve the Chinese people's health by participating in sports and physical activity, aligned to the health, physical activity, and sport-related SDGs. According to the national fitness plan (NFP), sports are a vital part of promoting healthy living in Chinese society and prevent NCDs. An industrial revolution of sport has been started in China under which the Chinese government is introducing several effective measures to achieve the goal of "Healthy China" by constructing the environment for sports and physical activity. The NCDs are the primary threat of life in China, according to the WHO. Sports play a vital role in the prevention of NCDs in the shape of increasing physical activity among the Chinese people. Besides, Chinese leaders said, "Sports play an essential role in promoting a healthy lifestyle and in building China's soft power in line with SDG 17 (Strengthening adopting and revitalizing the Sustainable Development Global Partnership). The optimistic aim of the National Fitness Plan (NFP) is to increase the involvement of athletics, boost nutrition, and create awareness of safe living. ${ }^{34}$

\section{China's Progress Towards Healthy China Under SDGs}

China unveiled China's National Strategy for the adoption of the 2030 Sustainable Development Agenda in September 2016. The Government of China has launched at national and international levels the 13th Five-Year Plan 
for Socio-Economic Growth to successfully pursue the Sustainable Development Agenda 2030. The vision of China's national plan is "innovative, coordinated, green, open and shared development." The Chinese government has implemented the Agenda of 2030 SDGs in every sector, and several targets (SDGs) have been achieved as early harvest. ${ }^{35}$ Healthy China-related progress under SDGs is outlined below;

- China is making substantial strides to attain SDGs for health, and maternal mortality has dropped to 19.9 per 100,000 . In comparison, the child mortality rate was lowered to 7.5 and 10.2 per 1000 , respectively. It will be of sufficient assistance in achieving the correct SDG goal. The Chinese government has launched a "Healthy China" program to tackle severe illnesses. $^{36}$ The targets for MMR, U5MR, and NMR had already been met for the SDG of 2030 by China, which had a high institutional distribution rate and almost a universal coverage of the vaccine in 2016. However, the achievement index of the family planning needs does not meet the modern contraception methods, which is expected to reach 76.6 by 2030 because of the unmet needs of single mating women. $^{22}$ In recent decades, children's undernutrition has significantly improved, while overweight and obesity in China have emerged as a new threat to public health. The stunting rate decreased from $16.3 \%$ to $8.1 \%$ for children aged 6 and under and wasting decreased from $2.6 \%$ to $2.0 \%$ for the years 2002 to 2013 . However, from $6.5 \%$ to $8.4 \%$ from 2002 to 2013, overweight rates increased. ${ }^{37}$

- The NCDs become the leading life hazard for Chinese citizens. The Chinese government concentrates most on eradicating NCDs by strengthening the mental and physical wellbeing of the population by promoting physical exercise and sports events. In the health field, an early assessment, early detection, and first care centers have been set up by the Chinese government for chronic diseases. Health administration incorporated obesity and diabetes in public health programs to provide rural and metropolitan people with free care. "Good life for everyone" has been placed into action in line with health-related SDGs under the subject "three reductions and threefold health" to encourage health awareness and a safe lifestyle to enhance Chinese people's fitness. ${ }^{36}$ China's coverage of maternal, neonatal, and child health care, infectious diseases and NCDs has improved significantly while the treatment and control rate for hypertension and diabetic disease remains small. China has produced tremendous results. China may still face significant challenges when controlling NCDs by reaching the SDG 3 target for NCDs (ie, by 2020 to reduce almost one-third the number of premature deaths from NCDs). ${ }^{22}$ Premature mortality by men with NCDs has not been expected to substantially decrease by 2030 due mainly to ongoing risk factors such as smoking, alcohol, and insufficient physical activity. There is no evidence that China would also soon reduce it is overweight and obesity rates.

- In addition to providing funding, China faces many barriers to widening its access to health services. In its 12th five-year plan, the Chinese Government substantially increased its health spending. The average annual increase in government health spending over the 2011-2016 period has been $17.3 \%$ significantly higher than the rate of economic growth. ${ }^{38}$ The Healthy China 2030 Agenda, the 13th Five Year Public Health Policy, the 13th Five Year Strategy for Promoting the Promotion of Fair Access to Essential Public Health Facilities, and demographic and family planning regulation all covered sexual health. The Decision on the adoption and improvement of the two-child national policy and the administration of family planning services was released to guarantee access to reliable family planning services.

- The Healthy China 2030 Plan ensures that smoking is banned in public areas, and road traffic incidents have been regulated by the framework of "lane safety accountabilities." The climate, water contamination, and cigarettes have been successfully regulated for life and safety. Throughout the 60 towns, an extensive surveillance program was established to track the impact of air emissions on human health. In 18 cities, a smoke-free health law was introduced. ${ }^{36}$ The prevalence of smoking and the use of alcohol for Chinese men and women are around 19 times and six times higher. The idea of an "ecological community" became enshrined in law and created the nation's consensus that "succinct waters and green mountains are valuable." The Chinese government is promoting low-carbon industries, such as renewable energy technologies and low-carbon cities with better mass transit and power generation, in tackling 
climate change. Energy intensity and carbon dioxide emissions dropped by $3.1 \%$ and $4.0 \%$ in 2018 over the previous year.

\section{Conclusion}

United Nations General Assembly adopted a global development framework in September 2015, named Sustainable Development Goals (SDGs). Agenda 2030 is acknowledged sport as an essential tool to implement the SDGs. The 13th socioeconomic development five-year plan has been introduced by the Chinese government, which is compatible with SDGs. The biggest life threat to Chinese people is NCDs due to physical inactivity. The Chinese government is focusing more on the promotion of physical activity through sports to achieve the SDGs regarding health. The Chinese state council introduced a national fitness strategy in June 2016 to improve the whole nation's physical fitness and then further improve the health level by 2020 . Sport is a vital tool to promote healthy living and physical activity in Chinese society. China is developing a "Soft Power" by supporting the sports and physical activity under The Agenda 2030 for sustainable development, further strengthening the global partnership of China in global matters. A program "Healthy Living for all" has been implemented with the theme of "three reductions and threefold health" under the health-related SDGs to achieve the target of Healthy China 2030. China is making tremendous progress towards the goal of Healthy China in multidimensional. To meet challenges and achieve healthrelated SDGs, China must take more coordinated steps. In those areas where the SDG targets (in maternal and child health and nutrition) have already been achieved in China, the government should summarize the experiences and best practices be distributed to other low- and middleincome nations which, through cooperation under the Belt and Road Initiative, develop their national strategies for advancing the SDG in health. Moreover, the Chinese government should make more investment in public transport, renewable energy, and public sports facilities to achieve health-related SDGs more comprehensively.

\section{Funding}

Current article is a part of "Study on the Government Cultivation of Spontaneous Sports Organizations in China". Funded by The National Social Science Fund of China (16BTY033, 2016.8-2021.12, PI: DaiJianhui).

\section{Disclosure}

The authors report no conflicts of interest in this work.

\section{References}

1. Spencer G, Corbin JH, Miedema E. Sustainable development goals for health promotion: a critical frame analysis. Health Promot Int. 2018;34(4):847-858. doi:10.1093/heapro/day036.

2. General Assembly UN. Transforming our World: the 2030 Agenda for Sustainable Development. United Nations Population Fund. 2015. Available from: https://www.unfpa.org/resources/transforming-ourworld-2030-agenda-sustainable-development. Accessed June 18, 2020.

3. Global Sports. Global sustainable development through the power of sport. Intelligence. Available from: https://intelligence.globalsports jobs.com/sport-a-powerful-tool-to-achieve-the-sustainabledevelopment-goals. Accessed June 18, 2020.

4. Sport for Development and Peace Towards Achieving the Millennium Development Goals. Available from: https://www.spor tanddev.org/en/article/publication/sport-development-and-peacetowards-achieving-millennium-development-goals. Accessed June 18, 2020.

5. The contribution of sports to the achievements of the sustainable development goals: a toolkit for action. Available from: https:// www.sdgfund.org/sites/default/files/report-

sdg_fund_sports_and_sdgs_web.pdf. Accessed June 9, 2020.

6. Millington R, Darnell SC. Sport, Development and Environmental Sustainability. Routledge: Abingdon, Oxon; 2020.

7. Edington DW, Schultz AB, Pitts JS, Camilleri A. The future of health promotion in the 21st century: a focus on the working population. $\mathrm{Am}$ $J$ Lifestyle Med. 2015;10(4):242-252. doi:10.1177/1559827615605789.

8. Whitelaw S. Settings' based health promotion: a review. Health Promot Int. 2001;16(4):339-354. doi:10.1093/heapro/16.4.339.

9. Dooris M. Holistic and sustainable health improvement: the contribution of the settings-based approach to health promotion. Perspect Public Health. 2009;129(1):29-36. doi:10.1177/1757913908098881.

10. Shanghai Consensus on healthy cities; Geneva: World Health Organization; 2016. Available from: http://www.who.int/healthpromo tion/conferences/9gchp/9gchp-mayors-consensus-healthy-cities.pdf? ua $=1$. Accessed December 23, 2019.

11. Flórez DA. International Case Studies of Smart Cities. Medellin, Colombia; 2016. doi:10.18235/0000406.

12. Lees SJ, Booth FW. Sedentary Death syndrome. Can J Appl Physiol. 2004;29(4):447-460. doi:10.1139/h04-029.

13. Jakovljevic MB, Milovanovic O. Growing burden of non-communicable diseases in the emerging health markets: the case of BRICS. Front Public Health. 2015;3. doi:10.3389/ fpubh.2015.00065.

14. Zhang H, Loi SM, Zhou SA, et al. Dementia literacy among community-dwelling older adults in Urban China: a cross-sectional study. Front Public Health. 2017;5. doi:10.3389/fpubh.2017.00124.

15. Mokdad AH. Actual causes of death in the United States, 2000. JAMA. 2004;291(10):1238. doi:10.1001/jama.291.10.1238.

16. Lausanne: Achieving SDGs through Sport: partnerships and institutional responses for greater coherence and effectiveness; 2017. Available from: http://www.metropolelemanique.ch/docs/05-102017-final-report.pdf. Accessed June 18, 2020.

17. Bailey R, Hillman C, Arent S, Petitpas A. Physical activity: an underestimated investment in human capital? J Phys Act Health. 2013;10(3):289-308. doi:10.1123/jpah.10.3.289.

18. Werff HVD. Sport Clubs in Europe. Springer; 2015:243-272.

19. Yelamos GM, Carty C, Clardy A. Sport: a driver of sustainable development, promoter of human rights, and vehicle for health and wellbeing for all. Sport Business Manage. 2019;9(4):315-327. doi:10.1108/sbm-10-2018-0090. 
20. The Role of Sport in Achieving the Sustainable Development Goals. UN Chronicle. United Nations, United Nations. Available from: https://unchronicle.un.org/article/role-sport-achieving-sustainabledevelopment-goals. Accessed December 24, 2019.

21. International Society for Physical Activity and Health. The Bangkok declaration on physical activity for global health and sustainable development. $\quad B r \quad J$ Sports Med. 2017;51(19):1389-1391. doi:10.1136/bjsports-2017-098063..

22. Chen S, Guo L, Wang Z, et al. Current situation and progress toward the 2030 health-related Sustainable Development Goals in China: a systematic analysis. PLoS Med. 2019;16:11. doi:10.1371/journal. pmed.1002975.

23. World Health Organization. World Health Organization. Physical inactivity: a global public health problem; 2014. Available from: https://www.who.int/dietphysicalactivity/factsheet_inactivity/en/. Accessed November 18, 2019.

24. Song G, Chen C, Zhang J, Chang L, Zhu D, Wang X. Association of traditional Chinese exercises with glycemic responses in people with type 2 diabetes: a systematic review and meta-analysis of randomized controlled trials. J Sport Health Sci. 2018;7(4):442-452. doi:10.1016/ j.jshs.2018.08.004.

25. Wu F, Narimatsu H, Li X, et al. Non-communicable diseases control in China and Japan. Global Health. 2017;13:1. doi:10.1186/s12992017-0315-8.

26. Cerf ME. Sustainable Development Goal Integration, Interdependence, and Implementation: the Environment-EconomicHealth Nexus and Universal Health Coverage. Global Challenges. 2019;3(9):1900021. doi:10.1002/gch2.201900021.

27. The World Bank. Toward a Healthy and Harmonious Life in China: stemming the Rising Tide of Non Communicable Diseases; 2011. Available from: https:/www.worldbank.org/content/dam/Worldbank/ document/NCD_report_en.pdf. Accessed November 11, 2019.

28. Sun W, Li Y, Hu Y, et al. Perspectives on the training of chinese primary health care physicians to reduce chronic illnesses and their burden. Front Public Health. 2019;7. doi:10.3389/fpubh.2019.00168.

29. The Lancet. Physical Activity 2016: progress and Challenges. 2016. https://www.thelancet.com/series/physical-activity-2016. Accessed June 18, 2020.
30. Liang J, Li X, Kang C, et al. Maternal mortality ratios in 2852 Chinese counties, 1996-2015, and achievement of Millennium Development Goal 5 in China: a subnational analysis of the Global Burden of Disease Study 2016. The Lancet. 2019;393 (10168):241-252. doi:10.1016/s0140-6736(18)31712-4.

31. Wang L, Kong L, Wu F, Bai Y, Burton R. Preventing chronic diseases in China. The Lancet. 2005;366(9499):1821-1824. doi:10.1016/ s0140-6736(05)67344-8.

32. World Health Organization. Global health risks. Comparative risk assessment project, 2009. Available from: https://www.who.int/ healthinfo/global_burden_disease/GlobalHealthRisks_report_full.pdf. Accessed June 13, 2020.

33. Xinhua. China to increase rural access to sports facilities. China to increase rural access to sports facilities-Chinadaily.com.cn. Available from: http://www.chinadaily.com.cn/a/201907/20/ WS5d31f0eea310d83056400027.html. Accessed June 18, 2020.

34. Tan T-C. The transformation of China's National Fitness Policy: from a major sports country to a world sports power. Int J Hist Sport. 2015;32(8):1071-1084. doi:10.1080/09523367.2015.1036240.

35. China's Industrial Revolution of Sport. Available from: https:/www. hostcity.com/news/city-development/chinas-industrial-revolutionsport. Accessed 2019 November 19.

36. China's Progress Report on Implementation of the 2030 Agenda for Sustainable Development. 2017. Available from: http://www.chinada ily.com.cn/specials/China'sProgressReport2(CN).pdf. Accessed November 25, 2019.

37. National Health and Family Planning Commission. China Residents' Nutrition and Chronic Diseases Report 2015. Beijing: People's Medical Publishing House; 2016

38. National Health and Family Planning Commission. China Health and Family Planning Statistical Yearbook 2017. Beijing: Peking Union Medical College Press; 2017.
Risk Management and Healthcare Policy

\section{Publish your work in this journal}

Risk Management and Healthcare Policy is an international, peerreviewed, open access journal focusing on all aspects of public health, policy, and preventative measures to promote good health and improve morbidity and mortality in the population. The journal welcomes submitted papers covering original research, basic science, clinical \& epidemiological studies, reviews and evaluations,

\section{Dovepress}

guidelines, expert opinion and commentary, case reports and extended reports. The manuscript management system is completely online and includes a very quick and fair peer-review system, which is all easy to use. Visit http://www.dovepress.com/testimonials.php to read real quotes from published authors. 